\title{
Primera cita de corzo, Capreolus capreolus (Linnaeus, 1758) (Artyodactila, Cervidae) para la provincia de Alicante
}

\author{
C. Doménech, R. P. Doménech, A. Belda
}

Doménech, C., Doménech, R. P., Belda, A., 2019. Primera cita de corzo, Capreolus capreolus (Linnaeus, 1758) (Artyodactila, Cervidae) para la provincia de Alicante. Arxius de Miscel/lània Zoològica, 17: 187-192, Doi: https://doi.org/10.32800/amz.2019.17.0187

\begin{abstract}
First record of the roe deer, Capreolus capreolus (Linnaeus, 1758) (Artyodactila, Cervidae) from the province of Alicante. The first record of the roe deer, Capreolus capreolus (Linnaeus, 1758), from the Alicante province is reported. This species was identified by phototrapping in one of the mountainous regions in the north of this area. The various hypotheses of recolonization of the species in the area are considered, the most plausible being natural reintroduction due to expansion of the populations from neighbouring provinces.
\end{abstract}

Key words: Roe deer, Geographical distribution, Alicante, Hunting, Ungulates

Record published in Zenodo (Doi: 10.5281/zenodo.3479531)

Key words: Roe deer, Geographical distribution, Alicante, Hunting, Ungulates

Resumen

Primera cita de corzo, Capreolus capreolus (Linnaeus, 1758) (Artyodactila, Cervidae) para la provincia de Alicante. Se da a conocer el primer registro de recolonización del corzo, Capreolus capreolus (Linnaeus, 1758), en la provincia Alicante. La especie se ha localizado mediante fototrampeo en una de las comarcas montañosas situadas en el norte y el interior de dicho territorio. Se plantean igualmente las diferentes hipótesis de recolonización de la especie en la zona, siendo la más plausible la reintroducción natural por expansión de las poblaciones provenientes de provincias colindantes.

Cita publicada en Zenodo (Doi: 10.5281/zenodo.3479531)

Palabras clave: Corzo, Distribución geográfica, Alicante, Cinegética, Ungulados

Resum

Primera cita de cabirol, Capreolus capreolus (Linnaeus, 1758) (Artyodactila, Cervidae) per a la provincia d'Alacant. Es dona a conèixer el primer registre de recolonització del cabirol, Capreolus capreolus (Linnaeus, 1758), a la província d'Alacant. L'espècie s'ha localitzat

El @ [2019] del artículo pertenece al autor o autores; estos autorizan a la revista Arxius de Miscel/lània Zoològica la publicación del artículo bajo la licencia de Creative Commons Reconocimiento 4.0 que permite un uso no restringido, la distribución y la reproducción en cualquier medio, siempre que se citen los autores y la revista. 
mitjançant parament fotogràfic en una de les comarques muntanyoses situades al nord i a l'interior del territori esmentat. Es plantegen així mateix les diferents hipòtesis de recolonització de l'espècie a la zona, la més plausible de les quals és la reintroducció natural per expansió de les poblacions provinents de les províncies limítrofes. .

Cita publicada a Zenodo (Doi: 10.5281/zenodo.3479531)

Paraules clau: Cabirol, Distribució geogràfica, Alacant, Cinegètica, Ungulats

Received: 03/06/2019; Conditional acceptance: 06/09/2019; Final acceptance: 25/09/2019

C. Doménech, R. P. Doménech, Departament de Ciències Ambientals i Recursos Naturals, Universitat d'Alacant. Carretera de Sant Vicent del Raspeig s/n., 03690 San Vicent del Raspeig, Alacant, España (Spain).- A. Belda, Departament de Ciències de la Terra i del Medi Ambient, Universitat d'Alacant, Carretera de Sant Vicent del Raspeig s/n., 03690 San Vicent del Raspeig, Alacant, España (Spain).

Corresponding author: C. Doménech: carles.domenech.perez@gmail.com

\section{Introducción}

La Comunidad Valenciana cuenta actualmente con poblaciones estables de siete de las ocho especies de artiodáctilos distribuidos por la península ibérica. Por un lado, el jabalí, Sus scrofa, Linnaeus, 1758; el ciervo rojo, Cervus elaphus Linnaeus, 1758; el gamo Dama dama (Linnaeus, 1758); el muflón, Ovis aries musimon (Pallas, 1811), y la cabra hispánica, Capra pyrenaica Schinz, 1838, están presentes en las tres provincias valencianas. Por otro, el corzo, Capreolus capreolus (Linnaeus, 1758), presente únicamente en Castellón y Valencia, y, por último, el arruí, Ammotragus lervia (Pallas, 1777), que únicamente habita en el sur de Valencia y en Alicante (Belda et al., 2015; Banc de Dades de la Biodiversitat, 2019).

En los últimos años, y aunque en diferente grado, el área de distribución y el número de individuos de cada una de estas especies ha experimentado una notable expansión. Este crecimiento es debido probablemente a la menor presión cinegética y al éxodo rural, estando este último directamente relacionado con una menor actividad agropecuaria y, de forma subsecuente, con el incremento de terrenos baldíos, propicios en mayor medida para estos ungulados (Acevedo et al., 2005). El ejemplo paradigmático de esta expansión en el territorio valenciano es el del corzo, especie ausente desde principios del siglo XX pero que actualmente y desde los años noventa (Tellería y Virgós, 1997), presenta poblaciones afianzadas en el interior con rápida progresión hacia el área costera (Jiménez et al., 2012). De este modo, el área de distribución natural del corzo se extiende por Europa, la región del Cáucaso y Turquía. En España, sus poblaciones se extienden, en el norte, por la Cordillera Cantábrica, los Montes de León, los Pirineos, el Sistema Ibérico y el Sistema Central, mientras que en el sur se encuentran localizados en los Montes de Toledo, Sierra Morena y las sierras de Cádiz y Jaén (San José, 2007; Mateos-Quesada, 2017).

Por otro lado, y basada en un corto periodo de seguimiento de mamíferos mediante fototrampeo, esta nota aporta el primer registro de corzo en territorio alicantino desde su desaparición. Así, el objetivo de la misma es dar a conocer la presencia de esta especie de ungulado en un territorio donde no había sido citada anteriormente. 


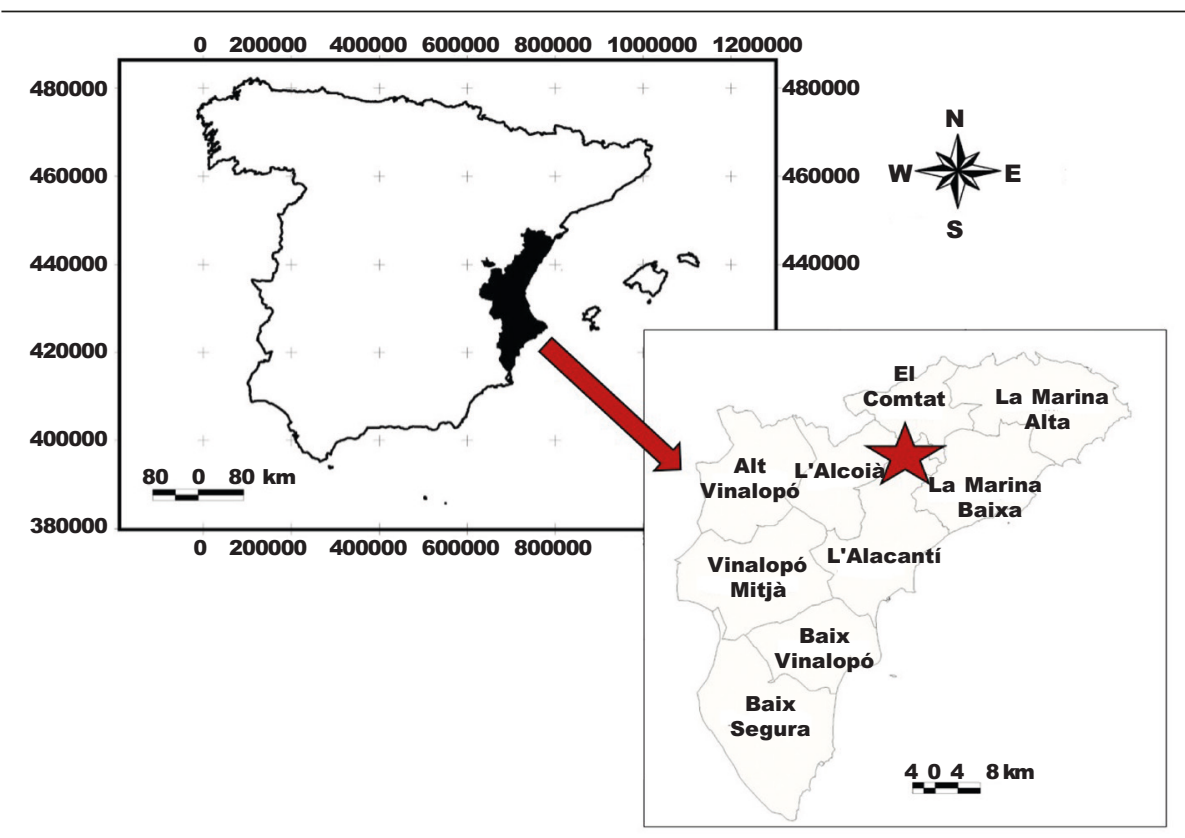

Fig. 1. Ubicación del punto de contacto de la cita entre las comarcas de l'Alcoià i el Comtat (Alicante).

Fig. 1. Location of the study area, situated between the regions of Alcoià and Comtat (Alicante).

\section{Material y métodos}

\section{Marco geográfico}

El área de estudio comprende las comarcas de L'Alcoià i El Comtat, situadas al norte de la provincia de Alicante, Comunidad Valenciana (fig. 1). Estas comarcas se elevan sobre sobre el nivel del mar desde unos $400 \mathrm{~m}$ hasta el punto más alto de la provincia, situado a unos $1.558 \mathrm{~m}$, en la Sierra de Aitana. Hidrográficamente se beneficia del paso de varios ríos, siendo el Serpis el más destacable por su mayor caudal. Así, la vegetación de esta demarcación forestal está compuesta por un biotopo mixto de pino carrasco, encina, maquia mediterránea (GVA, 2019a) y explotaciones agrarias en monocultivo donde predominan el olivo, el almendro y, en menor medida, algunos cereales (GVA, 2019b).

Registro fotográfico y tratamiento de imágenes

Con el objetivo de estudiar la diversidad de vertebrados en el área, se colocó una cámara de fototrampeo modelo Trail Camera GEOD032AB $®$ durante un periodo de 21 días, entre el 29 de abril y el 19 de mayo de 2019. El dispositivo se situó en una zona de paso, a unos $200 \mathrm{~m}$ de un arroyo y sobre el tallo de un pino carrasco a $30 \mathrm{~cm}$ de altura, enfocándose el objetivo a $3 \mathrm{~m}$ de distancia sobre el plano horizontal. La cámara fue programada para realizar 
una fotografía con un periodo de reposo de dos minutos entre capturas, almacenándose estas posteriormente en una tarjeta de memoria SD de 16 GB. Además del contacto animal se registran datos adicionales como la temperatura, la fecha y la hora de captura. Como atrayente se usaron $300 \mathrm{~g}$ de maíz, $100 \mathrm{~g}$ de almendras y, ocasionalmente, carcasas de pollo o conejo, siendo repuestos dichos atrayentes manualmente cada dos días sobre las $12 \mathrm{~h}$, si era necesario. Igualmente, y para promover la persistencia de los animales en la zona, parte de estos elementos atrayentes se situaron bajo un montón de piedras

El tratamiento de imágenes (mejora del brillo y contraste) y la generación de mapas se realizó mediante Adobe $₫$ Photoshop portable CS6® y ArcGIS $₫$, respectivamente.

\section{Resultados}

Durante el periodo de estudio, el total de imágenes captadas fue de 246 . De estas fotografías, únicamente 106, divididas en 39 series de entre una y 12 fotografías cada una, mostraron especies de diferentes mamíferos presentes en la zona. En dichas series fotográficas se observaron: jabalí, Sus scrofa, en tres ocasiones; zorro, Vulpes vulpes (Linnaeus, 1758), en seis ocasiones, con cuatro individuos diferentes y mostrando dos de ellos grandes placas alopécicas posiblemente secundarias a escabiosis; conejo, Oryctolagus cunniculus (Linnaeus, 1758), en 18 ocasiones; gineta, Genetta genetta (Linnaeus, 1758), en dos ocasiones; ratón de campo, Apodemus sylvaticus (Linnaeus, 1758), en ocho ocasiones, y garduña, Martes foina Erxleben, 1777, en dos ocasiones.

El 7 de mayo de 2019, a las 18:56 horas, fue registrada una única imagen con encuadre parcial de un ejemplar hembra de corzo (para más información, véase la cita publicada en Zenodo (Doi: 10.5281/zenodo.3479531). No hubo más imágenes del ejemplar en ese día ni en días posteriores, siendo este el único registro de la especie en la zona (fig. 2).

Destacó igualmente la presencia de un perro, Canis lupus familiaris Linnaeus, 1758, y de un gato, Felis catus familiaris Linnaeus, 1758, observados en dos ocasiones cada uno.

\section{Discusión}

Aunque en la zona se llevan realizando estudios de fauna mediante el manejo de fototrampeo y transectos desde hace una década (Belda et al., 2017), el corzo no había sido detectado hasta la fecha en la provincia de Alicante. Aunque según la International Union for Conservation of Nature (IUCN, 2016) el corzo está catalogado como una especie de Preocupación Menor (LC), su presencia en un entorno salvaje de dicha provincia resulta de interés desde el punto de vista faunístico. En lo que se refiere a la selección de hábitat, coincide con un estudio realizado en el Sistema Central donde se observó la preferencia de la especie por los entornos con zarzales y rosales silvestres, parches con mayor cobertura de pastos y matorrales, caracterizados por su elevada humedad y productividad (Mateos-Quesada, 2017). Así, este documento certifica mediante una única instantánea la presencia de un ejemplar de dicha especie en la zona. El origen de este animal plantea dos hipótesis principales: introducción natural por expansión de poblaciones vecinas o, de forma análoga al caso del arruí en el norte de Alicante (Belda et al., 2015), fuga de ejemplares provenientes de cercados cinegéticos o de núcleos zoológicos vecinos.

Para corroborar o refutar la segunda hipótesis se estableció contacto telefónico con los dos únicos acotados de caza mayor y con un parque zoológico situados dentro de la provincia de Alicante. En dichas instalaciones se preguntó si se mantenían corzos, resultando la respuesta siempre negativa.

Por dicho motivo, y como contexto más probable, el ejemplar hallado podría provenir de provincias colindantes desde las que, obviamente, es posible su desplazamiento y que, por orden de probabilidad, serían Albacete, Valencia y, por último, Murcia. Las poblaciones 


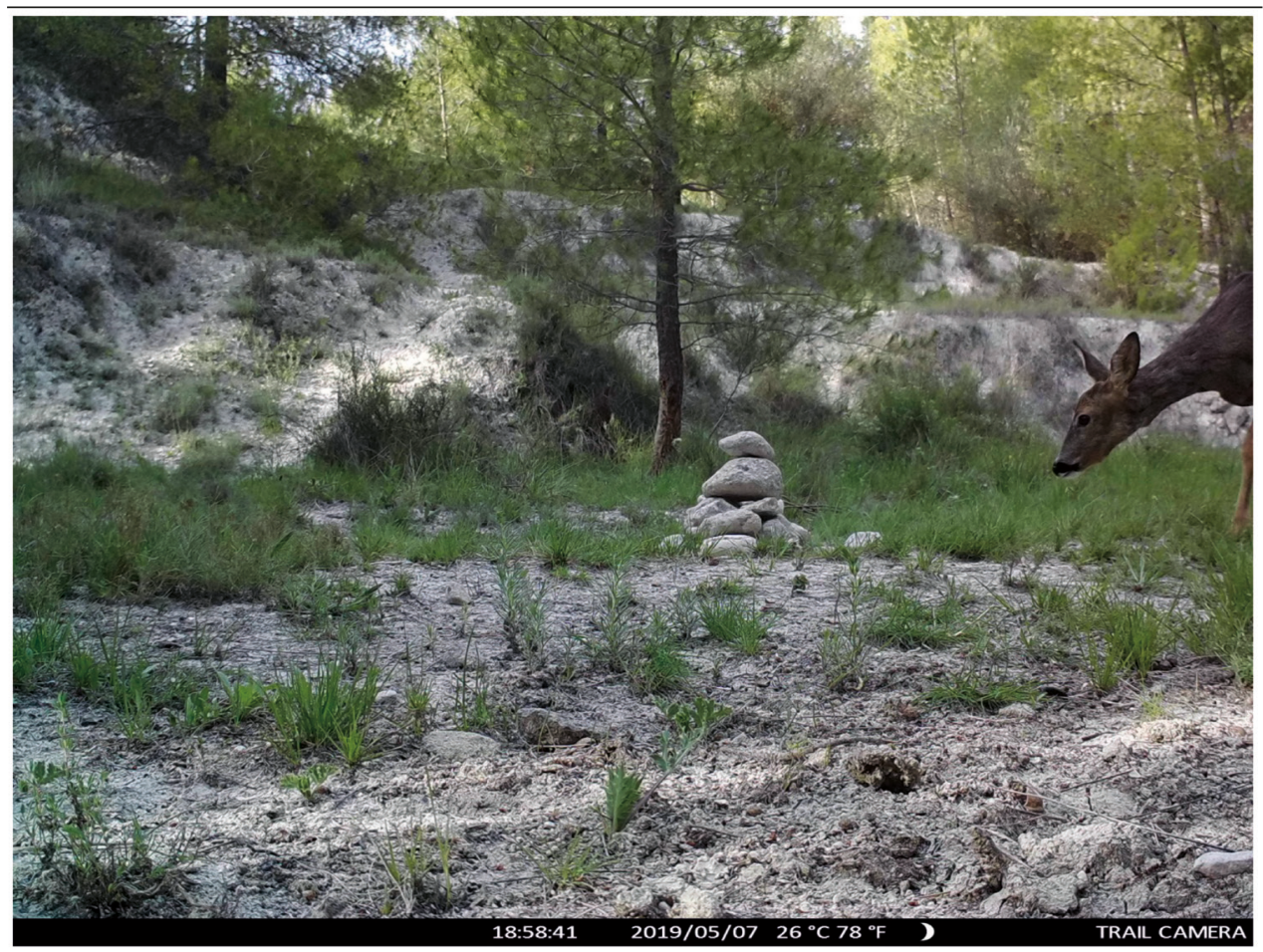

Fig. 2. Imagen de un ejemplar hembra de corzo (C. capreolus) tomada en el norte de la provincia de Alicante.

Fig. 2. Photo of a female roe deer (C. capreolus) taken in the north of the province of Alicante.

de corzos, más abundantes en Castilla-la Mancha, y un clima más favorable (el tercio sur de Alicante y la región de Murcia presentan grandes áreas con climas semiáridos) podrían facilitar el avance de las poblaciones.

Finalmente, y a modo de resumen, este nuevo hallazgo podría constituir el primer indicio de recolonización por vía natural del corzo en las montañas del interior de Alicante, hallazgo que podría ser, al igual que en los casos de Castellón y Valencia (Jiménez et al., 2012), el paso previo a la extensión de poblaciones de esta especie hacia zonas del litoral de la provincia. La información que se proporciona en la presente nota debe ser tenida en cuenta por parte de los gestores de los espacios naturales cercanos ya que la gestión de los ungulados genera cierta controversia por parte de cazadores, propietarios, entidades conservacionistas y la propia administración.

\section{Agradecimientos}

A Santos Rojo, profesor titular y doctor en Zoología por la Universidad de Alicante, por sus comentarios sobre el primer borrador, que han mejorado de forma substancial la calidad del texto definitivo. Al proyecto SIOSE-INNOVA, por la logística y el soporte cartográfico, así como por el asesoramiento técnico del grupo de trabajo. 


\section{Referencias}

Acevedo, P., Delibes-Mateos, M., Escudero, M. A., Vicente, J., Marco, J., Gortázar, C., 2005. Environmental constraints in the colonization sequence of roe deer (Capreolus capreolus Linnaeus, 1758) across the Iberian Mountains, Spain. Journal of Biogeography, 32: 1671-1680.

Banc de dades de la Biodiversitat, 2019. Generalitat Valenciana. www.bdb.gva.es/es

Belda, A., Belenguer, R., Zaragozí, B., Ferri, V., 2017. Presència del gat domèstic, Felis silvestris catus (Schreber, 1775), i del gat serval, Felis silvestris, en un espai natural protegit: el cas del Parc Natural Serra de Mariola (sud-est espanyol). Arxius de Miscel/lània Zoològica, 15: 253-263, https://doi.org/10.32800/amz.2017.15.0253.

Belda, A., Belenguer, R., Zaragozí, B., 2015. Situación del arruí Ammotragus lervia (Pallas, 1777) en la sierra de Mariola (SE español): distribución y aspectos ecológicos. Orsis, 29: $1-11$.

GVA, 2019a. El territori forestal de la Comunidad Valenciana. Generalitat Valenciana. www. agroambient.gva.es

- 2019b. Estadístiques agraries i pesqueres. Generalitat Valenciana. ww.agroambient.gva. es/va/estadisticas 1

IUCN, 2016. Capreolus capreolus. Deer Specialist Group. IUCN Red List of Threatened Species, http://www.iucnredlist.org/

Jiménez, J., Monsalve, M. A., Raga, J. A. (Eds.), 2012. Mamíferos de la Comunidad Valenciana. Colección Biodiversidad, 19. Conselleria d'Infraestructures, Territori i Medi Ambient. Generalitat Valenciana. Valencia.

Mateos-Quesada, P., 2017. Corzo - Capreolus capreolus. En: Enciclopedia Virtual de los Vertebrados Españoles: 2-31 (A. Salvador, I. Barja, Eds.). Museo Nacional de Ciencias Naturales, Madrid. http://www.vertebradosibericos.org/

San José, C., 2007. Capreolus capreolus (Linnaeus, 1758). En: Atlas y libro rojo de los mamíferos de España: 359-361 (L. J. Palomo, J. Gisbert, J. C. Blanco, Eds.). Dirección General para la Biodiversidad-SECEM-SECEMU, Madrid.

Tellería, J. L., Virgós, E., 1997. Distribution of an increasing roe deer population in a fragmented Mediterranean landscape. Ecography, 20(3): 247-252. 